\title{
LUBRICATION OF MEATUS AND CIRCUMCISION SITE FOR PREVENTION OF POST CIRCUMCISION MEATAL STENOSIS IN CHILDREN YOUNGER THAN TWO YEARS OLD
}

\author{
SK MONDAL ${ }^{1}, \mathrm{KHASINA}^{2}, \mathrm{MAHUQ}^{3}, \mathrm{MAALI}^{4}, \mathrm{MALAM}^{5}, \mathrm{MM} \mathrm{HUQUE}^{6}, \mathrm{JG} \mathrm{KHAN}^{7}$, \\ AKM MIZANUR RAHMAN ${ }^{8}$, S ISLAM
}

\begin{abstract}
Introduction: Approximately one in three men is circumcised globally, but there are relatively few data on the safety of the procedure ${ }^{1}$. Circumcision is a surgical procedure performed for centuries for medical, religious and several other reasons. Circumcision is the most common surgical procedure performed in boys through out the world. Meatal stenosis is one of its late complications. We evaluated the topical use of lubricant jelly (Vaseline- petroleum jelly) after circumcision in boys in order to reduce or prevent the risk of meatal stenosis.
\end{abstract}

Objective: To see the effectiveness of use of lubricants and to determine the functional outcome, that is prevention of post circumcision meatal stenosis.

Materials and Method: A randomized control trial was performed, in which two groups of boys younger than two years old underwent circumcision according to

1. Dr Susankar Kumar Mondal, Resident, Dept of Pediatric surgery, Dhaka Medical College \& Hospital

2. Dr Kaniz Hasina, Asst Prof, Dept of Pediatric surgery, Dhaka Medical College \& Hospital.

3. Dr Md Ashraf UI Huq, Assoc. Prof. Dept of Pediatric surgery, Dhaka Medical College \& Hospital

4. Dr Md. Ansar Ali, Dept of Pediatric surgery, Dhaka Medical College \& Hospital.

5. Prof. Md Mahbub-UI-Alam, Head of the Dept. of Pediatric Surgery, Dhaka Medical College \& Hospital.

6. Dr Muhammed Moinul Huque, Dept of Pediatric surgery, Dhaka Medical College \& Hospital

7. Dr Jaglul Gaffer Khan, Medical Officer,SOPD, Dhaka Medical College \& Hospital

8. Dr A K M Mizanur Rahman, Registrar Dept. of Pediatric Surgery, Dhaka Medical College \& Hospital

9. Dr. Shahnoor Islam, Assistant Prfessor, Dept of Pediatric surgery, Dhaka Medical College \& Hospital

Correspondence to : Dr Susankar Kumar Mondal, Resident, Dept of Pediatric surgery, Dhaka Medical College \& Hospital, E-mail: mondalsusankar@gmail.com dissection (sleeve) method. The parents in the study groups were strictly instructed to use petroleum jelly on the meatus and circumcision site at every morning or after each diaper change where necessary for three months, on the other hand parents in the control group were instructed not to use any lubricants or topical medication on the same site. The boys were followed up regularly and evaluated for meatal stenosis, bleeding and infection.

Results: A total of 120 boys, 60 in each group completed the study. None of the boys in the study group develop meatal stenosis, but $6(10 \%)$ in the control group develop meatal stenosis $(p<0.05)$. Infection of the circumcision site was seen in $1(0.6 \%)$ and $3(5 \%)$ children in the lubricant and control groups, respectively $(p<0.05)$ and bleeding was seen in $3(5.0 \%)$ and $6(10.0 \%)$ respectively.

Conclusion: Based on the findings of this study, it seems logical to use a lubricant jelly for prevention of post circumcision meatal stenosis and other complications.

Key Words: Circumcision, Lubricants, Meatitis, Meatal stenosis,Bleeding, Wound infection.

\section{Introduction}

Circumcision means removing the foreskin that naturally covers the glans penis ${ }^{2}$. Circumcision is a surgical procedure which is widely carried out among Muslims and the Jewish ${ }^{3}$. It is used for centuries to perform on the ground of medical, religious and several other reasons. Children undergoing circumcision certainly are at a risk for complications. Neonatal circumcision in Jordan remains a frequent surgical procedure that is performed by a variety of practitioners, including urologists, family practitioners, obstetricians, general surgeons and Mohels. Although the procedure is performed by multiple specialists, 
overall results are excellent. All surgeons seem circumcision is a simple operation, but still it is dangerous and carries potential risks to the patient. As a surgeon, we need to weigh up these risks carefully against the possible benefits of any surgical intervention ${ }^{4}$. Approximately $25 \%$ of the total world male population is circumcised and circumcision remains one of the oldest and commonest operations performed all over the world. The complication rates of the procedure range between $0.19 \%$ and $3.1 \%$. Despite this and many other similar recommendations, the procedure has continued to be performed even to a greater degree with virtually all children undergoing circumcision in the neonatal period in some communities ${ }^{5}$. Boys experience hemorrhage, infection, and ulceration; the urethral opening narrows due to scarring 6 . At present, approximately $70 \%$ of obstetricians, $60 \%$ of family practitioners, and $35 \%$ of pediatricians practice newborn circumcision ${ }^{7}$. The British Medical Association has recommended that circumcision should be performed only for medical reasons ${ }^{8}$. Routine neonatal circumcision has become a controversial issue in the past 2 decades as many of the previously accepted medical indications have come under considerable scrutiny ${ }^{7}$. Although many families choose to have their male infants circumcised for cultural, religious, or hygienic reasons, only a few accepted medical indications are recognized: phimosis, paraphimosis, balanitis and posthitis. Circumcision is also recommended in male infants and toddlers who develop UTIs and children who require clean, intermittent catheterization to facilitate this procedure ${ }^{7}$. Meatitis, an inflammation generally secondary to ammoniacal diaper irritation, has been cited as the underlying cause of secondary meatal stenosis. The lack of protection by the foreskin in the circumcised male is thought to correlate with an increased incidence of meatitis. Meatal narrowing has been noted to occur more commonly in the circumcised male. The formation of a ventral lip of tissue is characteristic of secondary meatal narrowing and may cause deflection of the urinary stream upward ${ }^{9}$. Circumcision is one of the most common surgical operations throughout the world, and meatal stenosis is one of its late complication ${ }^{10}$. Several studies have been carried out regarding appropriate age of circumcision, early and late complications of circumcision, the effect of circumcision on reducing the urinary tract infection \& comparing the different techniques for doing circumcision ${ }^{11,12,13,14}$.
Nonetheless, published study lack enough suggestions on post circumcision care, such as the use of mineral oils for reducing complications.

Some authors have reported routine use of lubricants to the meatal area after circumcision ${ }^{15}$. We decided to perform a randomized control trial to evaluate postoperative lubrication of meatus \& circumcision site for prevention of meatal stenosis.

\section{Materials and Methods}

It was a Randomized Control Trial study which was conducted in the Department of Pediatric Surgery Dhaka Medical College \& Hospital during the period of September 2008 to October 2009. Total 120 boys of less than two years of age were taken for the study \& a purposive sampling technique was done that was equally divided into two groups. Group A-study group, odd number- $1^{\text {st }}$ case \& every alternate case, Group B- control group; even number- $2^{\text {nd }}$ case $\&$ every alternate case.

The study design was approved by the ethical committee of Dhaka Medical College, Dhaka. Patients having severe congenital anomalies like hypospadius, web penis etc $\&$ age above two years were excluded from this study. Details history and clinical examination and relevant investigations like Blood for: $\mathrm{Hb} \%$, Bleeding Time \& Clotting Time, X-ray chest, urine for routine examination and culture were performed. Obtaining of informed written consent from legal guardians operations were performed under general anesthesia as a day case surgery. Just before operation all patients are strictly checked to exclude pre operative meatal stenosis by using $5 \mathrm{~F}$ lubricated feeding tube below age one year and $7 \mathrm{~F}$ lubricated feeding tube below two years of age. Passing of well lubricated feeding tube through the meatus exclude pre operative meatal stenosis ${ }^{16}$. All procedures were done by same surgical procedure by dissection (sleeve) method. Most of the operations were done by same surgeon. Suture materials of all patients were same (5-0 atromatic plain catgut ). After performing the procedure a povidone iodine soaked gauge piece was applied on operative site for few hours. Patients of study population were strictly instructed to apply simple petroleum jelly (Vaseline) locally at the site of circumcision site and meatus at every morning for three months. On the other site patients in the control group was instructed not to use any topical medications or petroleum jelly (Vaseline) on to the 

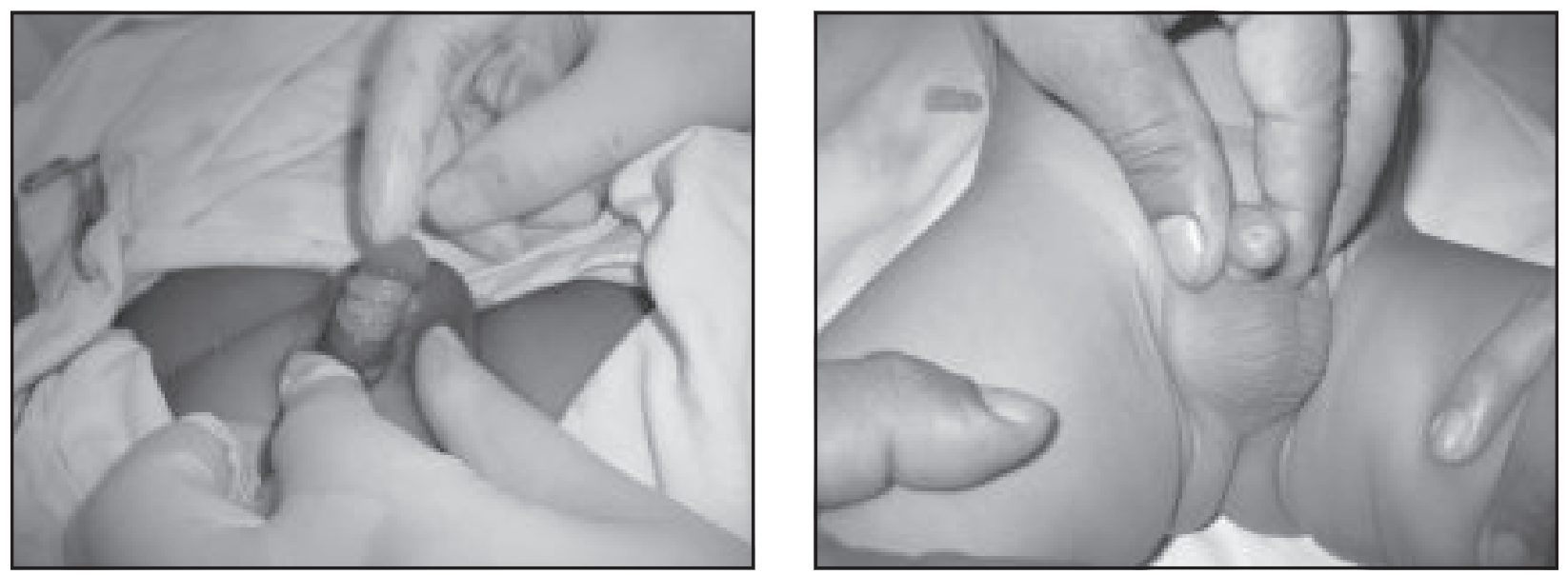

Fig.-1: Use of lubricants after circumcision and development of meatal stenosis without use of lubricant.

operative site. Total number of follow up were eight, within three months. First once in a week for one month, then twice in a month for two months. During follow up - the following points were noted-presence of small meatus with lateral traction ventral edges appears to be fused or not, abnormal strength or direction of urinary stream, discomfort with urination and incontinence, bleeding at the end of urination \& prolong emptying of bladder.

All data were recorded systematically in preformed data collection sheet. Data was plotted on Microsoft Excel and analyzed with SPSS version 15 , by using Chi square, $t$ test. 95\% confidence limits were taken. Probability value $<0.05$ were considered as level of significance. Quantitative data were expressed as mean and standard deviation and percentage.

\section{Results}

A total of 120 patients of age below two years who fulfilled the inclusion criteria were participated in the study. The mean age was $15.40 \pm 7.21$ months ( range, 1 months to 23 months ) for the children selected in the lubricant group and $17.35 \pm 7.01$ months ( range, 20 days to 23.5 months ) for those in control group $(p=0.136)$.

None of the children in the lubricant group develop meatal stenosis, while, $6(10 \%)$ in the control group develop post circumcision meatal stenosis $(p<0.05)$. Non specific meatitis was seen in $1(0.66 \%)$ and 3 $(5 \%)$ children in the lubricant and control groups, respectively $(p<0.05)$. Three boys $(5 \%)$ in the lubricant group and six boys (10\%) in the control group had post circumcision bleeding $(p<0.05)$.
Table-I

Distribution by age

\begin{tabular}{lccr}
\hline Age in months & \multicolumn{2}{c}{ Groups } & pvalue $^{*}$ \\
\cline { 2 - 3 } & Group A & Group B & \\
\hline $1-12$ & $33(55.0) \#$ & $20(33.3)$ & \\
$12-24$ & $27(45.0)$ & $40(66.7)$ & \\
Total & $60(100.0)$ & $60(100.0)$ & \\
Mean \pm SD & $15.40 \pm 7.21$ & $17.35 \pm 7.01$ & 0.136 \\
(Age in months) & & & \\
\hline
\end{tabular}

Table-II

Distribution of per operative complications by groups

\begin{tabular}{lccc}
\hline Hemorrhage & \multicolumn{2}{c}{ Groups } & pvalue $^{\star \star}$ \\
& Group A & Group B & \\
\hline Present & $03(5.0)^{\star}$ & $06(10.0)$ \\
Absent & $57(96.7)$ & $54(90.0)$ \\
\hline Total & 60 & 60
\end{tabular}

Table-III

Distribution of meatal stenosis by groups within three months

\begin{tabular}{lccc}
\hline & \multicolumn{2}{c}{ Meatal stenosis } & pvalue* $^{*}$ \\
& Group A & Group B & \\
\hline Present & 00 & 06 & 0.027 \\
Absent & 60 & 54 & \\
\hline Total & 60 & 60 & \\
\hline
\end{tabular}


Table-III shows the distribution of meatal stenosis by groups within three months. In Group A no one respondent had meatal stenois and in Group B 6 respondents had meatal stenosis after three months. There is statistical significant difference in post operative complication between the groups $p<0.05$

\section{Discussion}

Male circumcision is a common surgical procedure, but few epidemiological studies have reported frequency of adverse events, most commonly bleeding, infection and as a late complication commonly meatal stenosis. This is likely due to several factors directly associated with complications such as age at circumcision, training and expertise of the provider, the sterility of the conditions under which the procedure is undertaken and the indication (medical/cultural) for circumcision.

In general, complications (reported by parents) occur least frequently among neonates and infants than older boys, with majority of prospective studies in neonates and infants finding no serious complications, and relatively few other adverse events, which is minor and treatable ${ }^{17}$. Diagnosis of meatal stenosis has been reported in $0.9 \%$ to $11 \%$ of the boys undergoing circumcision ${ }^{18}, 19,20$. However, higher rates may be seen in areas in which the procedure is done by non qualified regional people ${ }^{21}$. Our present study showed that using petroleum jelly after circumcision was effective for reducing frequency of post circumcision meatal stenosis. We did not observe any case of meatal stenosis in children whose meatus and circumcision site was lubricated according to schedule for three months, while with the operation of the same surgeon, $10 \%$ children in control group developed meatal stenosis.

We observe very less frequent cases of post circumcision bleeding in boys lubrication of the meatus and circumcision site when compared with the control group. Bleeding has been reported as the most common early complication after circumcision and its prevalence was 3.33 to $10 \%$, depending on the experience and talent of the practitioner and the technique used ${ }^{22}$. Our main goal was to prevent meatal stenosis, but lubrication was also effective in reducing early episode of bleeding. We also achieved good results regarding infection in the meatus and circumcision site. Different statistical findings, ranging from $0.1 \%$ to $3.3 \%$, have been reported in other studies for the prevalence of infection at the circumcision site ${ }^{23}$. These figures depend on the practitioner skill and technique used. There were no similar studies to show the effect of lubrication on this kind of infection. Okeke reported application of bland petroleum jelly to the external urethral meatus in boys with chemical urethritis and yielding promising results ${ }^{24}$. Lubrication might be effective in reducing inflammation of the procedure site, and consequently, in reducing rate of infection.

\section{Conclusion}

Based on findings in this randomized control study, we can conclude that using petroleum jelly (Vaseline) on meatus and circumcision site after circumcision is effective for reducing post circumcision meatal stenosis and other complications. However more studies are needed to prove the effectiveness of lubricants for reducing post circumcision meatal stenosis and other complications.

\section{Acknowledgement:}

I would like to sincerely thank all my teachers, colleagues and others medical stuff, who helped me during this study period.

\section{References:}

1. Wallerstein E, Circumcision: The Uniquely American Medical Enigma, Urologic Clinics of North America, 1985: 12; 123-132.

2. Al-Ghazo MA and Banihani KE., Circumcision Revision in Male Children, Int Braz J Urol, 2006: 32; 454-458.

3. Allen JS, Summers JL, Wilkerson JE, Meatal caliberation of newborn boys. J Urol, 1972:107; 498.

4. Hutson J M., Circumcision: a surgeon's perspective, J Med Ethics, 2004:30; 238-240.

5. Okeke LI, Asinobi AA, Ikuerowo OS, Epidemiology of complications of male circumcision in Ibadan, Nigeria, BMC Urol, 2006 $: 6$.

6. Miller GP, Circumcision: A Cultural-Legal Analysis, Virginia Journal of Social Policy and the Law, 2002: 9; 497-585.

7. Angel CA and Cantu S Jr. Circumcision. Available from: www.emedicine.com, Updat2ed: Jan 25, 2010 [Access 12/03/2010]. 
8. Williams $\mathrm{N}$ and Kapila, Complications of circumcision, British Journal of Surgery, 2005: 80; 1231-1236.

9. Belman $A B$, Filmer BB, Immergut MA, , Schoenberg HW. , Urethral Meatal Stenosis in Males, Pediatrics, 1987: 61; 778-780.

10. Bazmamoun $\mathrm{H}$, Ghorbanpour M, Mousavi-Bahar $\mathrm{SH}$., Lubrication of Circumcision Site for Prevention of Meatal Stenosis in Children Younger Than 2 Years Old, Urol J, 2008 ; 5 ;233-236.

11. Kim D and Pang M. The Effect of Male Circumcision on Sexuality, BJU International, 2007: 99; 619-622.

12. Metcalf TJ, Osborn LM, Mariani EM., Circumcision:A Study of Current Practices, Clinical Pediatrics, 1983 : 22 ;575-579.

13. Miller GP., Circumcision: A Cultural-Legal Analysis, Virginia Journal of Social Policy and the Law, $2002: 9$; 497-585

14. Milos MF and Macris D,Circumcision: A Medical or a Human Rights Issue?, Journal of NurseMidwifery, 1992 : 37 ;875-965.

15. Okeke LI, Asinobi AA, Ikuerowo OS, Epidemiology of complications of male circumcision in Ibadan, Nigeria, BMC Urol, 2006 $: 6$.

16. Van Howe RS, Incidence of Meatal Stenosis following Neonatal Circumcision in a Primary Care Setting, Clinical Pediatrics, 2006 : 45 ; 49-54.
17. Weiss HA, Larke N, Halperin D, Inon Schenker I, Complications of circumcision in male neonates, infants and children: a systematic review, BMC Urology, 2010: 10.

18. Griffiths DM, Atwell JD, Freeman NV, A prospective survey of the indications and morbidity of circumcision in children, Eur Urol, $1985: 11$; 184-187.

19. Milos MF and Macris D,Circumcision: A Medical or a Human Rights Issue?, Journal of NurseMidwifery, 1992 : 37 ;875-965.

20. Van Howe RS, Incidence of Meatal Stenosis following Neonatal Circumcision in a Primary Care Setting, Clinical Pediatrics, 2006 : 45 ; 49-54.

21. Milos MF and Macris D,Circumcision: A Medical or a Human Rights Issue?, Journal of NurseMidwifery, 1992 : 37 ;875-965.

22. Santucci RA and Terlecki RP. Available from: www.emedicine.com Specialties > Urology > Common Problems of the Penis. Phimosis, Adult Circumcision, and Buried Penis. Last Updated: Apr 15, 2009[Access 12/03/2010].

23. Metcalf TJ, Osborn LM, Mariani EM., Circumcision: A Study of Current Practices, Clinical Pediatrics, 1983 : 22 ;575-579

24. Ozdemir E. Significantly increased complication risks with mass circumcisions, $\mathrm{Br} \mathrm{J}$ Urol, 1997; 80; $136-139$ 